\title{
Extent and nature of dual practice engagement among Iran medical specialists
}

\author{
Mahboubeh Bayat ${ }^{1}$, Gholamhossein Salehi Zalani ${ }^{1}$, Iraj Harirchi ${ }^{2}$, Azad Shokri ${ }^{3}$, Elmira Mirbahaeddin ${ }^{4}$, \\ Roghayeh Khalilnezhad ${ }^{5}$, Mahmoud Khodadost ${ }^{6,7}$, Mehdi Yaseri $^{8}$, Ebrahim Jaafaripooyan ${ }^{9}$ and Ali Akbari-Sari ${ }^{*}$
}

\begin{abstract}
Background: Dual practice (DP) by medical specialists is a widespread issue across health systems. This study aims to determine the level of DP engagement among Iran's specialists.

Methods: A pre-structured form was developed to collect the data about medical specialists worked in all 925 Iran hospitals in 2016. The forms were sent to the hospitals via medical universities in each province. The data were merged at the national level and matched using medical council ID codes, national ID codes, and eventually a combination of the first name, surname, and father's name.

Results: A total of 48345 records were collected for 30273 specialists from 858 (93\%) hospitals out of total 925 hospitals. Sixteen thousand eight hundred forty-nine (69\% of) specialists were non-faculty members and 6317 ( $26 \%$ of) specialists were employed on a contract basis. Eleven thousand six hundred and thirty-eight ( $47.7 \%$ of) specialists were engaged in DP on total. Female specialists had 0.78 times less DP chance; faculties compared to non-faculties had 0.65 times more DP chance and full-time geographic specialists compared to non-full-time specialists had 0.15 times more DP chance. DP was more frequent in specialists with higher age and more job experience and in provinces with more population, deprivation, and higher number of specialists per facility $(P<0.05)$.

Conclusions: The level of DP is relatively high among Iran medical specialists, especially in geographic full-time specialists. However, they are totally banned and they receive extra payment for being full-time; restrictive regulations and financial incentives without considering other factors might not eliminate DP in specialists and it should be addressed based on conditions of each country and regions inside the country.
\end{abstract}

Keywords: Medical specialists, Dual practice, Multiple jobs holding, Iran

\section{Background}

Dual practice (DP) or multiple jobs holding is considered as holding a job in more than one facility simultaneously. DP normally happens when a professional simultaneously works in public and private facilities, in two public facilities or in two private facilities $[1,2]$. Kiwanuka et al. define DP for healthcare professionals as having more than one medical job inside or outside public sector facilities [3]. Dual practice is relatively frequent

\footnotetext{
* Correspondence: akbarisari@tums.ac.ir

${ }^{9}$ Department of Health Management and Economics, School of Public Health, Tehran University of Medical Sciences, Poursina St, 16 Azar St, Bolvar Keshavarz, Tehran, Islamic Republic of Iran

Full list of author information is available at the end of the article
}

in healthcare, especially in physicians, nurses, midwives, and technicians. However, it seems that specialists have a greater tendency for DP [3-5].

In Austria, 100\% of specialists work in both public and private sectors at the same time, followed by $90 \%$ in Ireland, $80 \%$ in Bangladesh, $71 \%$ in Egypt, $70 \%$ in Indonesia, $65.7 \%$ in Australia, $61 \%$ in the UK, $43 \%$ in Portugal, 38\% in New Zealand, and 37\% in Denmark, and income increase is reported as the main reason for DP [1, 2, 4, 6-9].

The income gap between the specialists in the public and private sectors is the main reason to encourage physicians to leave the public sector or work simultaneously in the public and private sectors. Other driving reasons

(c) The Author(s). 2018 Open Access This article is distributed under the terms of the Creative Commons Attribution 4.0 International License (http://creativecommons.org/licenses/by/4.0/), which permits unrestricted use, distribution, and reproduction in any medium, provided you give appropriate credit to the original author(s) and the source, provide a link to the Creative Commons license, and indicate if changes were made. The Creative Commons Public Domain Dedication waiver (http://creativecommons.org/publicdomain/zero/1.0/) applies to the data made available in this article, unless otherwise stated. 
for this flow and multiple job holding can be factors such as lower chance of career development in the public sector, higher autonomy in the private sector, and insufficient infrastructure in public facilities [8].

DP has negative and positive effects in developing and developed countries; however, the negative effects far exceed the positive $[4,11]$. The positive consequence was the additional income for health workers that may have resulted in increasing the retention of skilled workers especially in deprived areas and decreasing the budgetary burden of the public sector. Among the negative consequences, this phenomenon has resulted in fragmentation of specialists' supply and decreased accessibility in the public sector, especially considering the division of specialists' working time in different locations [10]. Consequently, DP reduces hours of physicians' presence, imposes more pressure on nurses and other health professionals, and has negative impacts on the quantity and quality of services [1, 2, 11]. It also increases patient referrals from the public to private sectors which can lead to induced demand and increased healthcare costs [12]. Besides, the physicians who are involved in DP might become free riders of the public sector using equipment and resources or administrative services, and nurses of the public sector for private patients $[2,6,13]$.

The income gap between the public and private sectors in these countries is a key motivating factor for physicians to leave the public sector or work in both the public and private sectors [8]. Other factors that have been identified as driving the movement of physicians from the public to the private sector include lack of academic and career development opportunities in the public sector, poor infrastructure in public facilities, and greater autonomy in the private sector [8]. Bearing in mind the considerable negative impacts of DP, health systems in different countries address this issue differently based on their context and level of development. Developed countries normally apply partial restrictions through regulatory mechanisms while developing countries use some restricting and mandatory mechanisms $[14,15]$. However, these strategies may not always work. Efforts to ban DP in Greece from 1983 to 2002 failed due to lack of capacity to enforce it [10]. In some states of India where DP has been banned, weak enforcement and poor mechanisms to check the practice lead to failure in such obligations [16].

The current strategies used to control DP in Iran include complete ban for full-time geographic (FTG) specialists [17] and partial restrictions using different incentives for non-full-time specialists [18]. FTG physicians are the ones who are not allowed to be active in any other locations/sectors except their main occupation location. The first strategy refers to specialist physicians who are supposed to be full-time (54 h per week), and according to this law, physicians will receive remuneration for full-time status, which will eventually earn more than other doctors [17]. The latter one is related to other experienced non-full-time specialists who are motivated to work full-time in the public sector with no practice in the private sector through some benefits such as paying for having no office equal to their salaries and remuneration for full-time status for non-faculty members, about $60-65 \%$ of the salary, under the condition of permanent employment in the public sector (non-DP( [18].While each of these strategies might have different impacts on the workforce and health status in terms of appropriate management and control of DP, countries should design and adopt proper strategies according to their situations, and the first step for the adoption of effective strategies is to identify and explore the level, nature, and contributory factors of DP $[1,19]$. In Iran, there is limited evidence about the extent and nature of DP and its contributory factors $[14,20]$. This study aims to determine the level of DP engagement and its contributory factors among Iran's specialists.

\section{Methods}

Since there was no comprehensive data bank regarding medical specialists to detect their behaviors such as DP, we designed a data collection form to create a data bank and extracted physicians with DP through data matching and detecting duplicate data. Some studies from different countries were done through sampling and questionnaire $[4,8-10]$. We used this method as a novel method for decreasing the information bias.

\section{Data collection process}

A pre-structured form together with a manual about how to complete it were developed to collect the data about specialists who worked in Iran public and private hospitals in 2016. Study hospitals were all 925 Iranian hospitals including government teaching hospitals; hospitals from the Social Security Organization (SSO), armed forces, and the Ministry of Petroleum (MoP); and other public, private, and charity hospitals.

In each province of Iran, there is at least a government medical university directed by the Ministry of Health and Medical Education (MOHME) that is responsible for education (training of medical doctors, specialists, nurses, etc.) and health service delivery. These medical universities have their own healthcare facilities but at the same time they supervise all other public and private healthcare facilities in their catchment areas. Therefore, the forms were sent to all medical universities via MOHME and the medical universities sent the forms to all hospitals in their catchment areas. Medical universities then collected the data from hospitals of their 
catchment areas and sent them to MOHME using a pre-structured excel format that allowed integration of the data (Fig. 1). The forms and the excel files included information about specialists' name, surname, father's name, national ID code, medical council ID code, sociodemographic characteristics, recruitment and job status, and specifications of the employing hospitals and affiliating organization. The data were collected from each hospital for all specialists who worked in that hospital in 2016, full-time or part-time, temporarily or permanently. The hospitals were given 1 month to collect the data. For hospitals with no reply, a reminder at the end of month 1 and another reminder at the end of month 2 were sent. A combination of criteria from each individual specialist was used to merge the data at the province and national level and to identify whether a specialist was involved in DP. In the first step, the individual specialists' medical council ID code was used to match and merge the data. If this ID code was not available, the national ID code was used; eventually, if none of them was available for an individual, a combination of the first name, surname, and father's name or their initials were used. These procedures were performed by SQL functions of Access database (Table 1).

\section{Data quality control}

After receiving information from each hospital, via medical universities, the following steps were performed.

1) Preliminary assessment of data accuracy: The completed forms and excel files could potentially have two types of errors: "Instructions Errors" spotting through corresponding data with the provided instruction form and "Reference Errors" detected by matching a number of fields with the reference data banks that were already available at MOHME in terms of authenticity and accuracy. In case of having either of these errors, submitted

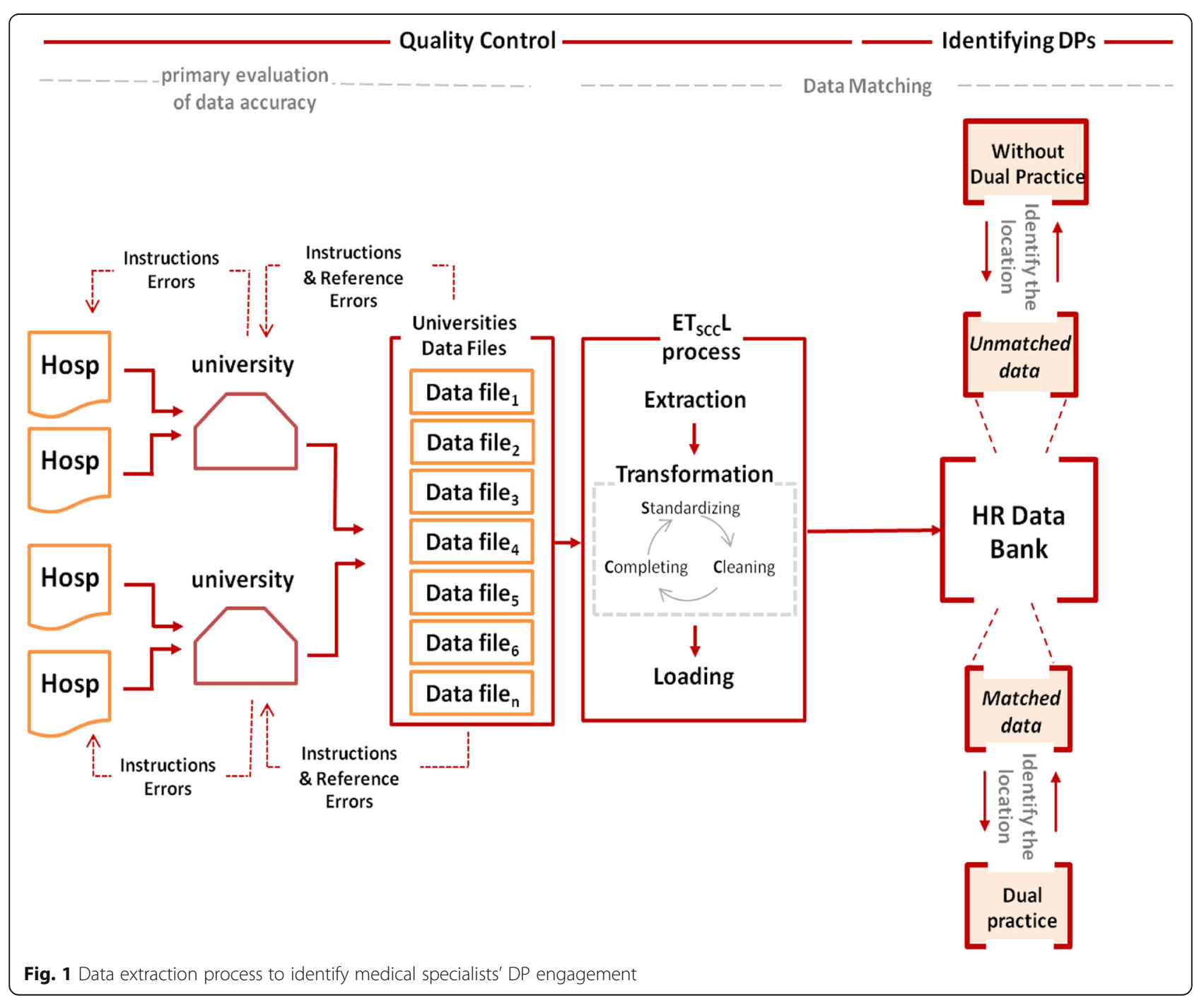


Table 1 Reference banks and their data items for completion of collected data

\begin{tabular}{|c|c|c|}
\hline Reference banks & & Data items in the reference bank \\
\hline Medical Council & $\rightarrow-$ & Medical council code, type of specialty, sex, age \\
\hline MOHME human resource management office & $-\longrightarrow$ & Faculty membership, experience, main occupation location \\
\hline MOHME hospital management office & $\rightarrow-$ & Full time status and experience \\
\hline Medical Council Office permit/license & $-\rightarrow$ & Office status \\
\hline List of clinics in Iran & $\rightarrow-\rightarrow$ & Name of clinic and its affiliation \\
\hline
\end{tabular}

forms were returned to the hospitals for correction and/or completion.

2) To minimize possible errors and increase accuracy of data collection and data merging, a standard extraction, transformation, and loading (ETL) method was adopted and used [16]. Separate data banks were developed for the MOHME (the headquarter, schools/research centers, hospitals and clinics), private sector organizations (hospitals, clinics, and physician offices), and other public sector organizations (hospitals and clinics). During transformation, the generated data banks entered a cycle of standardizing, cleaning, and completing.

- Standardizing: Based on the assessment, errors of the data in the Excel software were detected and corrected. They include misspellings, heterogeneity in naming, and heterogeneity in structure of the information.

- Cleaning: Accuracy and precision of the data was confirmed using recaptured data in data matching for each standardized data item with the reference banks.

- Completing: In this part, incomplete items consisting of faculty status, type of cooperation, demographic characteristics, etc. were completed through matching the data banks if needed. Also, one of the main objectives of this stage was completion of medical council codes for all records to proceed to the next stage which was identification of duplicate data between different extracted databases [18].

Finally, in the loading stage, required information for the study objective was extracted and refined from different sources and then loaded into one main concentrated data bank.

\section{Extraction of physicians with dual practice}

Noting the nature of dual practice and attendance of physicians in more than one service delivery location, to identify these types of physicians, a data matching model was applied and therefore duplicate data of medical council codes were detected among the health ministry banks and other public and private banks.
After identifying duplicate data (indicating physicians with dual practice), their main occupation location were specified based on their type of recruitment relation listed in the forms. Afterwards, share of dual practice among public sector specialists in each province and its relation with other characteristics of the physicians and conditions of provinces were determined based on dual practice definition made by this study considering DP as employment of public sector physicians in the private sector and other dissimilar public sectors in terms of ownership.

\section{Analysis of the results}

Logistic regression analysis was used to examine the relationships between DP and its contributory factors.

\section{Results}

\section{Status of the study specialists}

A total of 48345 records were collected for 30273 specialists from 858 (93\%) hospitals out of total 925 hospitals from which 24414 specialists were considered based on the definition of this study. The mean age of specialists was $46.23 \pm 9.33$ and $(63 \%$ of them were male, $68 \%$ of specialists were employed in medical university hospitals, $69 \%$ of all specialists were non-faculty members, and $26 \%$ of all specialists were employed on a contract basis (Table 2).

$22.23 \%$ of specialists were in Tehran (Fig. 2). KohgiluyehBoyer Ahmad, Ilam, and South Khorasan each had less than $1 \%$ of specialists.

\section{Dual practice status}

A total of 11638 (48\%) public sector specialists were engaged in dual practice from which 9575 were in service through MOHME and 62\% of non-full-time specialists had multiple job holdings (Table 3). Of 16849 non-faculty member specialists, $29 \%$ were academic $48.60 \%$ were non-academic and had multiple job holdings (Table 3). The highest rate of DP occurred in the provinces of Qazvin (72\%), Kohgiluyeh-Boyer Ahmad (70\%), Gilan (69\%), Alborz (57\%), and East Azerbaijan (59\%); compared to the provinces of Ilam, Hormozgan, Chaharmahal, and Bakhtiari, West Azarbaijan, Sistan, and Baluchestan had the lowest DP rates.

Based on this geographic distribution map which illustrates DP distribution in five groups, provinces at the 
Table 2 Demographic characteristics, university faculty membership, recruitment relation, and main occupation location of the specialists

\begin{tabular}{|c|c|c|}
\hline Variables & \#Specialists & \%Specialists \\
\hline \multicolumn{3}{|l|}{ Sex } \\
\hline Male & 15356 & 63.2 \\
\hline Female & 8937 & 36.8 \\
\hline \multicolumn{3}{|l|}{ Age groups } \\
\hline $40>$ & 6690 & 27.4 \\
\hline $40-45$ & 4185 & 17.1 \\
\hline $45-55$ & 9699 & 39.7 \\
\hline $55-65$ & 2792 & 11.4 \\
\hline $65<$ & 790 & 3.2 \\
\hline \multicolumn{3}{|l|}{ Main occupation location } \\
\hline University hospital & 20668 & 84.7 \\
\hline Social Security hospital & 2003 & 8.2 \\
\hline Armed forces hospital & 551 & 2.3 \\
\hline Petrochemical Company hospital & 240 & 1.0 \\
\hline Other public hospital & 533 & 2.2 \\
\hline MOHME headquarter & 370 & 1.5 \\
\hline Research center & 20 & 0.1 \\
\hline Healthcare center & 29 & 0.1 \\
\hline \multicolumn{3}{|l|}{ Faculty membership status } \\
\hline Faculty member & 7565 & 31.0 \\
\hline Non-faculty member & 16849 & 69.0 \\
\hline \multicolumn{3}{|l|}{ Full-time employment status } \\
\hline FTG* $^{*}$ & 8826 & 36.15 \\
\hline Non-full-time & 15588 & 63.85 \\
\hline \multicolumn{3}{|l|}{ Recruitment relation } \\
\hline Permanent & 6337 & 26.0 \\
\hline Peymani (semi-permanent) & 2644 & 10.8 \\
\hline Contractual & 6317 & 25.9 \\
\hline Zarib K & 5082 & 20.8 \\
\hline Payam avar & 20 & 0.1 \\
\hline Other & 2868 & 11.7 \\
\hline Unspecified & 1146 & 4.7 \\
\hline
\end{tabular}

"Full-time geographic (FTG) physicians are the ones who are not allowed to be active in any other locations/sectors except their main occupation location

national borderline and the deprived provinces had a lower rate of DP compared to the provinces in the center or advantaged areas (Fig. 3).

\section{Factors contributing to dual practice}

Female specialists had less chance of dual practice engagement with the private sector (odds ratio 0.76, $p<0.05$ ). Similarly, faculty physicians to non-faculty ones $(\mathrm{OR}=0.65)$ and full-time geographic physicians to non-full-time physicians had less chance of DP engagement $(\mathrm{OR}=0.15)$. Specialists with the age 40 years and more, individuals with more than 5 years of job experience, and physicians with permanent public sector employment relation had also more DP $(p<0.05)$.

The total ratio of specialist per 10000 population showed no significant correlation with DP $(p>0.05)$. However, there was a significant increase in DP with the increase of population. Specialists' DP also increased (1.01 times) when adding one public hospital and also adding one private hospital. In addition, there was significant association between the share of private hospitals (proportion of private hospital to the total hospitals) with $\mathrm{DP}(\mathrm{OR}=1.6, P=0.0001)$. There was also an inverse correlation between regions' deprivation and DP. Each unit of reduction in regional deprivation is correlated with 2.05 times less DP.

\section{Discussion}

In the present study, we used data matching to identify dual practitioners in a data bank which is created through our national survey while some studies used linking data between current registers $[8,21]$. The difference of our study with the mentioned studies is that we had to create a cross-sectional data bank to study DP in the first place as in most developing countries there are no routinely registered data for the activities of physicians [10]. Furthermore, to our knowledge, this study of 24293 specialists in Iran is one of the largest to investigate DP engagement in all regions of the country (Table 4). Some other studies were done through sampling and questionnaire $[4,8-10]$. However, to consider different countries, based on objective of the study, two response biases might occur including, first, having a small sample of dual practitioners in the countries, especially in regions with small private sectors and, second, avoiding the truth presented by physicians in a selfreporting method where DP is banned. However, in Iran and similar countries where DP is legally banned, using the self-reporting method may result in information bias. Unlike some other studies which used the self-reporting method $[4,10]$, this study collected data from employers rather than employees.

Findings show that 11638 (47.7\%) specialists in Iran engage in Dual practice which is significantly lower than Austria (100\%), Ireland (90\%), the UK (63\%), Australia (65.7\%), Bangladesh (80\%), Indonesia (70\%), and Egypt (71\%) $[1,14,19,20,22]$. This wide variation between the countries may be due to each country's specific situations including number of workforce and supply [8, 21, 23]. There are currently two approaches for control of DP in Iran; complete ban for FTG specialists and partial restrictions using different incentives for non-full-time specialists [18]. We also presented our results for these two categories. We found that $60 \%$ of non FTG specialists engage in DP despite implementing incentive mechanisms. 


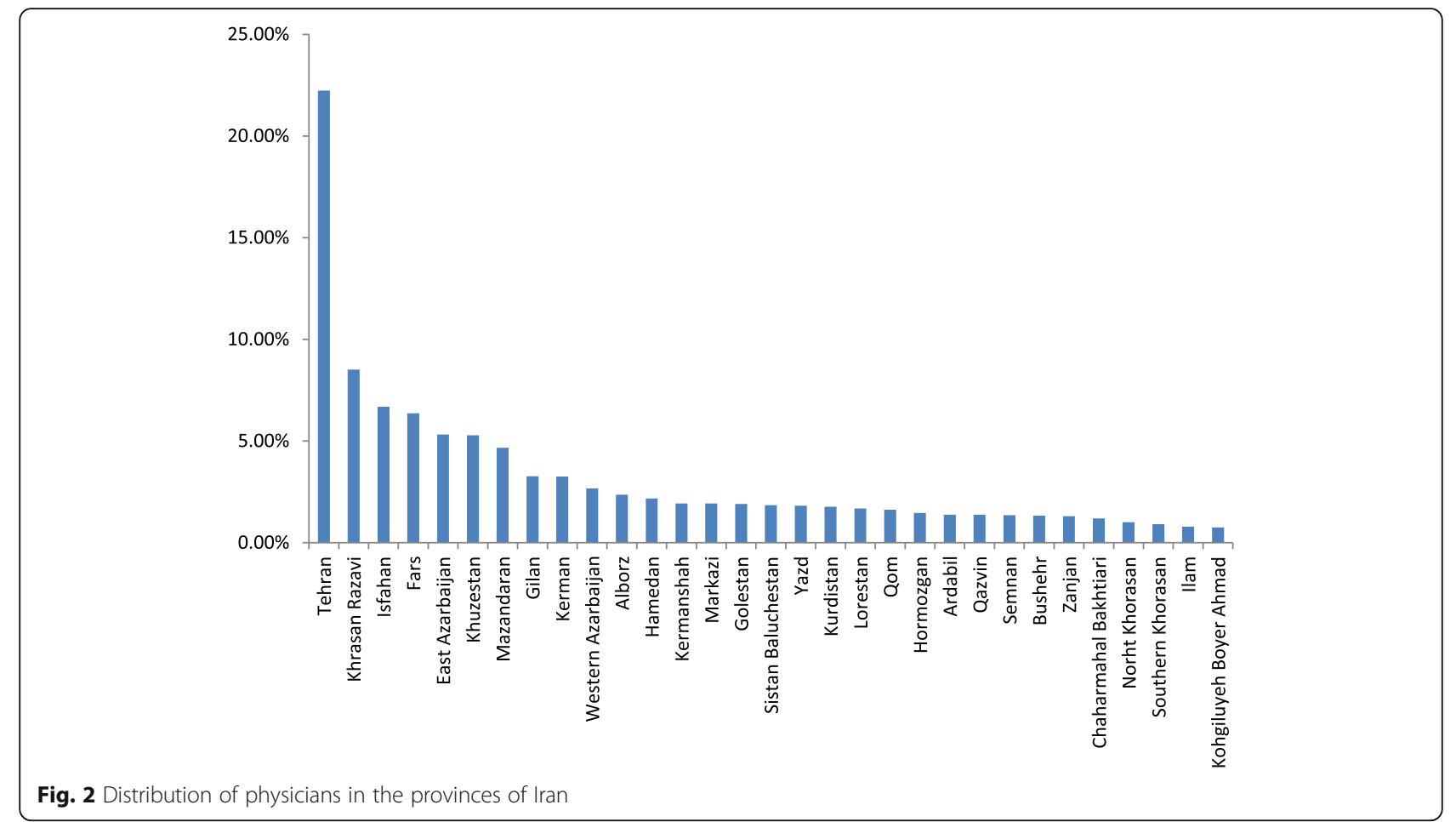

This shows that using the same strategy, there is still more DP in Iran compared to New Zealand (38\%), Portugal (43\%), and Denmark (37\%) [4, 8, 9]. Moreover, in FTG specialists, despite complete ban, $24 \%$ of them are engaged in DP. This is similar to China where with complete ban on DP, $29.6 \%$ of physicians are engaged in DP due to increase of income [4]. The same situation is reported from Mozambique where $21 \%$ of specialists are engaged in DP [24].This shows that even complete ban has not routinely eliminated DP in many countries. The main factor affecting DP despite the banning strategies is financial influences. Higher payments by the private sector along with the government's inability to pay specialists comparing to the

Table 3 Dual practice status of specialists by faculty membership status and full-time recruitment

\begin{tabular}{lll}
\hline & Total & \\
\cline { 2 - 3 } & $\#$ & $\%$ \\
\hline Affiliated organization & 9575 & 45.40 \\
MOHME & 2063 & 62.00 \\
$\quad$ Other public organs & & \\
Faculty membership & 3450 & 45.60 \\
$\quad$ Faculty member (academic) & 8188 & 48.60 \\
Non-faculty member & & \\
Full-time status & 9594 & 61.55 \\
$\quad$ Non-full-time & 2044 & 23.16 \\
FTG & 11638 & 47.70 \\
Total dual practice &
\end{tabular}

private sector can lead to ignoring restrictive rules of DP [25-27]. In addition, inflexibility of the rules and mechanisms of control may increase the tendency of doctors towards the private sector $[12,28,29]$.

We found that DP is reduced in deprived areas, regions with less population, areas with lower number of hospitals, and proportion of private hospitals $(p<0.05)$. This study showed that deprived provinces have lower level of DP and Tehran (capital) has a high level of DP. In Africa, regions with more facilities (2.2 per 10000 population) had the most DP engagement (0.7 per 10 000 population). Moreover, it reported that DP is more frequent in areas with more service delivery units, more inpatient facilities, more operation capacities, more private hospital, and higher income [6]. McPake also found that DP is more frequent in areas with higher population, higher human development index, and areas with more physicians [7]. Findings of the present study are consistent with the mentioned findings. Probably one of the reasons for less prevalence of DP in nonurban and deprived areas is the poor development of the private sector and shortage of DP opportunities; therefore, the public sector remains the main provider of services. As studies have shown in areas where the private sector has better facilities, the chance for professionals to work simultaneously in the private sector will be greater [30-32]. In addition, other reasons especially in some developing countries include strategies such as post-graduate compulsory commitments [33] similar to Zarib $\mathrm{K}$ specialists in Iran who have mandatory 


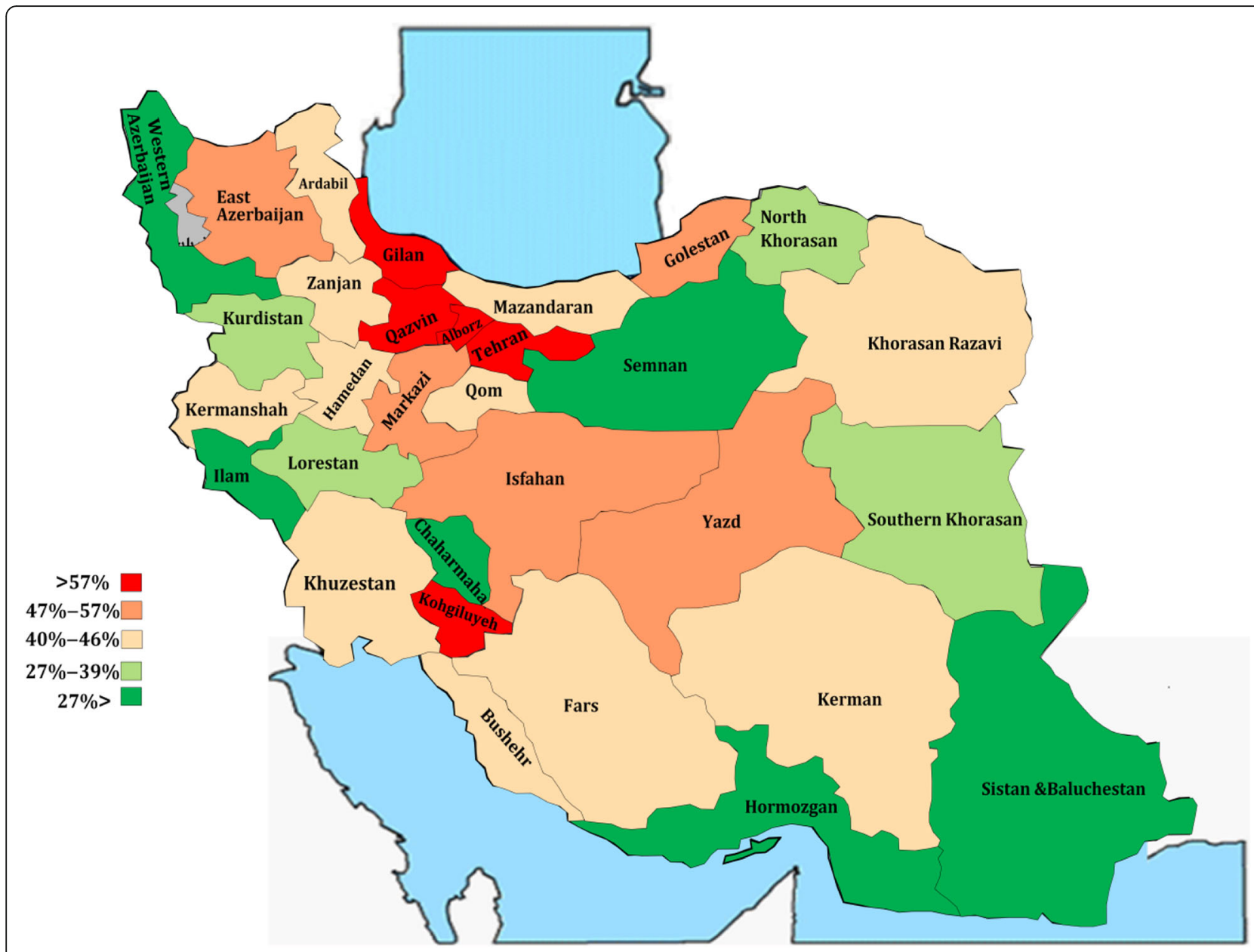

Fig. 3 Map of geographical distribution of Iran's specialists engaged in dual practice

commitments to work in deprived areas [18], and enforcing it through approving regulations in which they are not legally allowed through private practice [28]. Since these strategies have been developed in response to the shortage of specialists in these areas, they can affect DP prevalence in deprived areas as for the context of differences in the level of DP between urban and rural areas. Factors such as age, gender, social status, and professional characteristics of health workers have been also discussed; however, it seems they are not considered for policy making as of yet [2].

We found that female specialists were less likely to be engaged in dual practice in the private sector. In Norway, DP level among men and women were 25.0\% and $14.2 \%$ respectively [8]. Socha and Bech also reported 2.1 times more DP in men compared with women [34]. McPake also found that men are more likely to have dual practice [35]. One of the reasons for this difference could be due to variation of marginal utility of income that is higher for males [36]. It means that the change in human satisfaction resulting from an increase or decrease in an individual's income is higher among men. Therefore, men tend to have more income and the private sector is one way for them to increase their income [37]. Creating a balance between work and life is a decisive factor for women's working hours and their DP. For example, having a new child or having a large family size showed a prominent negative impact on female's DP [21]. Specialists with higher age and job experience had also more DP which is in line with other studies $[18,38]$. Chawla has shown that aging and increase in expertise, skills, and reputation cause more attractiveness for the private sector to secure higher payments to physicians [39]. It is argued that elder physicians who had already established a reputation in the public sector engage more in dual practice. In Iran, young physicians with diplomas have mandatory commitments to work in the public sector and it is named as Zarib $\mathrm{K}$ full-time physicians who are subject to Act for Physicians \& Paramedics Services [2]; on the other hand, since young physicians have fewer years of job experience and consequently they are less 
Table 4 Correlation between specialists' characteristics and the province features on dual practice engagement of public sector specialists

\begin{tabular}{|c|c|c|c|c|c|}
\hline & \multirow[t]{2}{*}{ Odds ratio (OR) } & \multicolumn{2}{|c|}{ 95\% confidence interval } & \multirow[t]{2}{*}{$P$ level } & \multirow[t]{2}{*}{$P$ variable } \\
\hline & & Lower limit & Upper limit & & \\
\hline \multicolumn{6}{|l|}{ Physician characteristics } \\
\hline \multicolumn{6}{|l|}{ Sex } \\
\hline Male & 1 & & & & \\
\hline Female & 0.756 & 0.715 & 0.8 & 0.022 & 0.001 \\
\hline \multicolumn{6}{|l|}{ Age } \\
\hline$<40$ & 1 & & & & \\
\hline $40-45$ & 1.196 & 1.099 & 1.301 & 0.001 & 0.001 \\
\hline $45-55$ & 2.116 & 1.966 & 2.277 & 0.001 & \\
\hline $55-65$ & 5.651 & 5.065 & 6.304 & 0.001 & \\
\hline $65<$ & 3.176 & 2.735 & 3.688 & 0.001 & \\
\hline \multicolumn{6}{|l|}{ Experience } \\
\hline$\leq 5$ & 1 & & & & 0.001 \\
\hline $6-14$ & 1.359 & 1.249 & 1.479 & 0.001 & \\
\hline $15-25$ & 5.645 & 5.071 & 6.284 & 0.001 & \\
\hline $25<$ & 4.033 & 3.504 & 4.643 & 0.001 & \\
\hline \multicolumn{6}{|l|}{ Employment status } \\
\hline Permanent & 1 & & & & \\
\hline Zarib K & 0.218 & 0.197 & 0.241 & 0.001 & 0.001 \\
\hline Payam avar & 0.051 & 0.007 & 0.386 & 0.004 & \\
\hline Peymani (semi-permanent) & 0.431 & 0.391 & 0.476 & 0.001 & \\
\hline Contractual & 1.035 & 0.961 & 1.115 & 0.362 & \\
\hline Others & 0.779 & 0.709 & 0.856 & 0.001 & \\
\hline Unspecified & 1.730 & 1.502 & 1.992 & 0.001 & \\
\hline \multicolumn{6}{|l|}{ Faculty membership status } \\
\hline Non-faculty & 1 & & & & \\
\hline Faculty & 0.647 & 0.607 & 0.690 & 0.001 & 0.001 \\
\hline \multicolumn{6}{|l|}{ Full-time status } \\
\hline Non-FTG & 1 & & & & \\
\hline FTG & 0.146 & 0.136 & 0.157 & 0.001 & 0.001 \\
\hline \multicolumn{6}{|l|}{ Provincial characteristics } \\
\hline \multicolumn{6}{|c|}{ Total specialists (per 10000 population) } \\
\hline$\leq 2.5$ & 1 & & & & \\
\hline $2.5-4$ & 1.795 & 0.919 & 3.505 & 0.087 & 0.091 \\
\hline $4-5$ & 1.957 & 0.834 & 4.593 & 0.123 & \\
\hline $5 \geq$ & 5.038 & 1.341 & 18.933 & 0.017 & \\
\hline \multicolumn{6}{|l|}{ Population } \\
\hline$\leq 500000$ & 1 & & & & \\
\hline $500000-2000000$ & 1.589 & 1.225 & 2.061 & 0.001 & 0.001 \\
\hline $2000000-5000000$ & 2.201 & 0.978 & 4.957 & 0.057 & \\
\hline $5000000<$ & 2.670 & 1.022 & 6.975 & 0.045 & \\
\hline
\end{tabular}


Table 4 Correlation between specialists' characteristics and the province features on dual practice engagement of public sector specialists (Continued)

\begin{tabular}{|c|c|c|c|c|c|}
\hline & \multirow[t]{2}{*}{ Odds ratio (OR) } & \multicolumn{2}{|c|}{$\underline{95 \% \text { confidence interval }}$} & \multirow[t]{2}{*}{$P$ level } & \multirow[t]{2}{*}{$P$ variable } \\
\hline & & Lower limit & Upper limit & & \\
\hline Extent of regional deprivation* & 2.053 & 1.498 & 2.813 & 0.001 & 0.001 \\
\hline Number of hospitals & 1.008 & 1.001 & 1.016 & 0.031 & 0.031 \\
\hline Number of private hospitals & 1.009 & 1.001 & 1.017 & 0.021 & 0.021 \\
\hline Share of private hospitals ${ }^{* *}$ & 1.590 & 1.341 & 1.886 & 0.001 & 0.001 \\
\hline
\end{tabular}

"Regional deprivation: the regional with lowest deprivation rate. Deprivation rate is ranked by the level of deprivation that showed with numbers 3 to 5 . Depending on the region's conditions, the most deprived region has the lowest rate (coefficient of deprivation of service points for doctors and paramedics. Tehran: Ministry of Health and Medical Education 2002 2002. Report No.: Contract No.: 24243)

${ }^{* *}$ Share of private hospitals: proportion of private hospitals to the total hospitals in a province

known/branded, they have less capacity of presence in the private market competing with senior physicians; therefore, they normally have lower level DP.

The present study is one of very limited number of studies which used a comprehensive approach to collect and analyze data for specialists from all Iran hospitals to explore the level of DP and its contributory factors.

\section{Conclusions}

This study found that despite implementation of financial and non-financial incentives and facilities to retain specialists in the public sector in form of full-time or even with the existence of complete restriction laws, a significant proportion of physicians still engage in DP. With the current social demand and increased confidence of people on the private sector, this phenomenon seems inevitable. It appears that retention of specialists in public hospitals might not be feasible solely through enforcement of regulations, without considering other factors including the competition of the private sector in attracting experienced and senior physicians of the public sector. Considering a complete ban on DP might lead to movement of senior and experienced physicians from the public sector and drainage of these centers from experienced specialists. Enforcement of regulations that restrict DP might be more feasible than regulations with complete ban. Moreover, a multi-approach strategy is needed to control DP. This might include tax regulations, income cap, and limitation in work hours and number of patients visited/admitted in the private sector. In addition, we recommend the method we applied since, to our knowledge, it can alleviate research limitations in developing countries where there is no routine data registers, through a robust way of data gathering by creating a data bank and its indirect approach to address DP is specifically useful for the countries where DP is banned.

\section{Abbreviations}

DP: Dual practice; ETL: Extraction, transformation, and loading; FTG: Full-time geographic; MOHME: Ministry of Health and Medical Education; MoP: Ministry of Petroleum; SSO: Social Security Organization

\section{Acknowledgements}

We are sincerely grateful of the managers and expert staffs in Iran's ministry of health and medical education headquarter for their support and guidance, and the ones in medical universities for their assistance through our discussions and for sharing their valuable opinions.

\section{Funding}

This study received no funding.

\section{Availability of data and materials}

The data that support the findings of this study are available from Iran Ministry of Health and Medical Education (MOHME), i.e., HRM office, but restrictions apply to the availability of these data, which were used under license for the current study and so are not publicly available. Data are however available from the authors upon reasonable request and with permission from the Center for Health Human Resources Research and Studies (CHHRRS).

\section{Authors' contributions}

GSZ, MB, MK, MY, EJ, and EM contributed to the study conception, MB, MK, EM, and AS gathered the data design, and all authors were involved in analysis and interpretation process of data. MB, AS, and EM drafted and translated the manuscript and all the authors contributed by their comments of improvement in several revisions to reach a final manuscript. All authors read and approved the final manuscript

\section{Ethics approval and consent to participate}

The Center for Health Human Resources Research and Studies in MOHME ethically assessed and approved the study methodology and ethical considerations with respect to the confidential data from specialists' records.

\section{Consent for publication}

The medical sciences universities of each province committed to provide an informed consent for the records of the specialists so that all individual information, e.g., name, surname, and national ID codes, remain highly secured for confidentiality during all stages of this study.

\section{Competing interests}

The authors declare that they have no competing interests.

\section{Publisher's Note}

Springer Nature remains neutral with regard to jurisdictional claims in published maps and institutional affiliations.

\section{Author details}

${ }^{1}$ Center for Health Human Resources Research \& Studies, Ministry of Health and Medical Education, Tehran, Islamic Republic of Iran. ${ }^{2}$ Department of Surgery, School of Medicine, Tehran University of Medical Sciences, Tehran, Islamic Republic of Iran. ${ }^{3}$ Social Determinants of Health Research Center, Kurdistan University of Medical Sciences, Sanandaj, Islamic Republic of Iran.

${ }^{4}$ Telfer School of Management, University of Ottawa, Ontario, Canada.

${ }^{5}$ Health Management and Economics Research Center, Iran University of 
Medical Sciences, Tehran, Islamic Republic of Iran. ${ }^{6}$ Department of Epidemiology, School of Public Health, Shahid Beheshti University of Medical Sciences, Tehran, Islamic Republic of Iran. ${ }^{7}$ Department of Epidemiology, School of Public Health, Iran University of Medical Sciences, Tehran, Islamic Republic of Iran. ${ }^{8}$ Department of Epidemiology, School of Public Health, Tehran University of Medical Sciences, Tehran, Islamic Republic of Iran. ${ }^{9}$ Department of Health Management and Economics, School of Public Health, Tehran University of Medical Sciences, Poursina St, 16 Azar St, Bolvar Keshavarz, Tehran, Islamic Republic of Iran.

Received: 29 July 2017 Accepted: 25 October 2018 Published online: 20 November 2018

\section{References}

1. García-Prado A, González P. Policy and regulatory responses to dual practice in the health sector. Health Policy. 2007;84:142-52.

2. Ferrinho P, Van Lerberghe W, Fronteira I, Hipólito F, Biscaia A. Dual practice in the health sector: review of the evidence. Hum Resour Health. 2004;2:1-17.

3. Gonzalez P. Should physicians' dual practice be limited? An incentive approach. Health Econ. 2004;13:505-24.

4. Russo G, McPake B, Fronteira I, Ferrinho P. Negotiating markets for health: an exploration of physicians' engagement in dual practice in three African capital cities. Health Policy Plan. 2014;29:774-83.

5. Jan S, Bian Y, Jumpa M, Meng Q, Nyazema N, Prakongsai P, Mills A. Dual job holding by public sector health professionals in highly resource-constrained settings: problem or solution? Bull World Health Organ. 2005;83:771-6.

6. Hipgrave DB, Hort K. Dual practice by doctors working in south and East Asia: a review of its origins, scope and impact, and the options for regulation. Health Policy Plan. 2014;29:703-16.

7. García-Prado A, González P. Whom do physicians work for? An analysis of dual practice in the health sector. J Health Polit Policy Law. 2011;36: 265-94.

8. Cheng TC, Joyce CM, Scott A. An empirical analysis of public and private medical practice in Australia. Health Policy. 2013;111:43-51.

9. Alaref J, Awwad J, Araujo E, Lemiere C, Hillis SA, Özaltin E: To Ban or Not to Ban? Regulating Dual Practice in Palestine. Health Systems \& Reform. 2017;3: 42-55.

10. McPake B, Russo G, Tseng F-M. How do dual practitioners divide their time? The cases of three African capital cities. Soc Sci Med. 2014;122:113-21.

11. Chue P. Incentives to dual practice new institutional economic analysis of Canada's mixed public-private health sector. University of Puget Sound, Department of Economics; 2007.

12. González P, Macho-Stadler I. A theoretical approach to dual practice regulations in the health sector. J Health Econ. 2013;32:66-87.

13. Globerman S, Vining A: A policy perspective on" mixed" health care financial systems of business and economics. J Risk Insur 1998;65:57-80.

14. Babashahy S, Akbarisari A. Assessment and analysis of international experiences in dual practice in public and private settings of healthcare system and regulatory mechanisms. Hakim Res J. 2013;16:98-106.

15. González P. On a policy of transferring public patients to private practice. Health Econ. 2005;14:513-27.

16. Berman P, Cuizon D. Multiple public-private jobholding of health care providers in developing countries. An exploration of theory and evidence Issue paper-private sector London: Department for International Developmnent Health Systems Resource Centre Publication; 2004.

17. Iran IPo: Administrative recruitment regulations for faculty members. Tehran: Islamic Parliament of Iran. 2010;1(3):58.

18. Iran IPo: Administrative recruitment regulations for non-faculty members. Tehran: Islamic Parliament of Iran; 2012;54:17.

19. Socha KZ, Bech M. Physician dual practice: a review of literature. Health Policy. 2011;102:1-7.

20. Sari AA, Babashahy S, Ghanati E, Naderi M, Lotfi SMT, Manesh AO, Razavi SHE. Implementing the full-time practice in Iran health system; perceptions of the medical university chancellors on its challenges, consequences and effective solutions. J Kerman Univ Med Sci. 2013;20:40-51.

21. Johannessen K-A, Hagen TP. Physicians' engagement in dual practices and the effects on labor supply in public hospitals: results from a register-based study. BMC Health Serv Res. 2014;14:1.

22. Song J, Wang D, BAO Y-b, YU G. Study on a metadata-driven ETL approach. Minimicro Syst Shenyang. 2007;28:2167.
23. Christen P. Data matching: concepts and techniques for record linkage, entity resolution, and duplicate detection. Springer Science \& Business Media; 2012.

24. Bir A, Eggleston K. Physician dual practice: access enhancement or demand inducement. Tufts University Department of Economics Working Paper; 2003. p. 11.

25. Mossialos E, Allin S, Davaki K. Analysing the Greek health system: a tale of fragmentation and inertia. Health Econ. 2005;14:S151.

26. Gruen R, Anwar R, Begum T, Killingsworth JR, Normand C. Dual job holding practitioners in Bangladesh: an exploration. Soc Sci Med. 2002;54:267-79.

27. Socha K, Bech M. Dual practitioners are as engaged in their primary job as their senior colleagues. Dan Med J. 2012;59:A4375.

28. Ferrinho P, Van Lerberghe W, Fronteira I, Hipólito F, Biscaia A. Dual practice in the health sector: review of the evidence. Hum Resour Health. 2004;2:14.

29. Anderson I, Meliala A, Marzoeki P, Pambudi E: The production, distribution, and performance of physicians, nurses, and midwives in Indonesia: an update. In The World Bank. Washington; 2014:1-56.

30. Paina Bergman L. Dual practice in Kampala, Uganda: a mixed methods study of management and policy: Johns Hopkins University; Baltimore;2014.

31. Basu S, Andrews J, Kishore S, Panjabi R, Stuckler D. Comparative performance of private and public healthcare systems in low-and middleincome countries: a systematic review. PLoS Med. 2012:9:e1001244.

32. Kotzee T, Couper I. What interventions do South African qualified doctors think will retain them in rural hospitals of the Limpopo province of South Africa. Rural Remote Health. 2006;6:581.

33. Frehywot $\mathrm{S}$, Mullan $\mathrm{F}$, Payne $\mathrm{PW}$, Ross $\mathrm{H}$. Compulsory service programmes for recruiting health workers in remote and rural areas: do they work? Bull World Health Organ. 2010;88:364-70.

34. Ahmed SM, Hossain MA, RajaChowdhury AM, Bhuiya AU. The health workforce crisis in Bangladesh: shortage, inappropriate skill-mix and inequitable distribution. Hum Resour Health. 2011;9:3.

35. Hoyler M, Finlayson SR, McClain CD, Meara JG, Hagander L. Shortage of doctors, shortage of data: a review of the global surgery, obstetrics, and anesthesia workforce literature. World J Surg. 2014;38:269-80.

36. Wordsworth S, Skåtun D, Scott A, French F. Preferences for general practice jobs: a survey of principals and sessional GPs. Br J Gen Pract. 2004;54:740-6.

37. Bir A, Eggleston K. Physician dual practice: access enhancement or demand inducement. Indonesia: Tufts University, Medford; 2003.

38. Ma C, Fouly H, Li J, D'Antonio P. The education of nurses in China and Egypt. Nurs Outlook. 2012;60:127-33 e121.

39. Set guidelines for health sector evolution plan.Retrieved 11/12/2018, from http://medsab.ac.ir/uploads/hse_chapter_930207_1400.pdf.

\section{Ready to submit your research? Choose BMC and benefit from:}

- fast, convenient online submission

- thorough peer review by experienced researchers in your field

- rapid publication on acceptance

- support for research data, including large and complex data types

- gold Open Access which fosters wider collaboration and increased citations

- maximum visibility for your research: over 100M website views per year

At BMC, research is always in progress.

Learn more biomedcentral.com/submissions 